\title{
Ghetto o cruzada: deslaicizar la laicidad
}

\author{
CARlos ARBOLEDA MORA \\ Universidad Pontificia Bolivariana (Colombia) \\ carlos.arboleda@upb.edu.co
}

\begin{abstract}
Resumen
Este trabajo tiene como objetivo mostrar lo que es una sana laicidad en la sociedad actual pluralista, multicultural, democrática y diversa. En primer lugar se presentan dos tentaciones de la iglesia hoy: refugiarse en el ghetto y cerrarse al mundo dando razón a los fundamentalistas laicos que la consideran como algo privado, o salir a la cruzada a imponer sus creencias y su mensaje. Luego se analiza el proceso histórico de formación del pluralismo, de la laicidad y de la libertad religiosa con énfasis en los modelos norteamericano y francés. Se concluye con una visión de lo que es la laicidad en la doctrina de la iglesia católica hoy y una propuesta de lo que debe ser el verdadero pluralismo y la sana laicidad hoy.
\end{abstract}

Palabras clave: laicismo, sana laicidad, pluralismo, ghetto, cruzada.

\section{Ghetto or crusade: desecularize the secularism}

\begin{abstract}
This article has as aim show what is a healthy secularism in the current pluralist, multicultural, democratic and diverse society. First, it presents two temptations of the church today: to shelter in the ghetto and to be closed to the world giving reason to the lay fundamentalists who consider faith to be something private, or to go out to the crusade to impose Christian beliefs and message. Then there is analyzed the historical process of formation of the pluralism, of the secularism and of the religious freedom emphatically in the models North American and French. The article concludes with a vision of what is the secularism in the doctrine of the catholic church today and a proposal of what must be the real pluralism and the healthy secularism today.
\end{abstract}

Key words: Secularism, healthy secularism, pluralism, ghetto, crusade.

Magister en Historia de la Universidad Nacional de Colombia. Licenciado en Ciencias sociales de la Universidad Gregoriana de Roma. Doctor en Filosofía de la UPB en Medellín. Docente en la UPB y director del grupo de investigación Religión y cultura. Ha publicado entre otros los siguientes libros: Experiencia y testimonio (2011), Pluralismo, tolerancia y religión en Colombia (2012), Profundidad y cultura (2006), Experiencia, filosofía y testimonio (2008), Paganismo y cristianismo en la fiesta colombiana (2012). 


\section{1. ¿Ghetto o cruzada?}

Hoy las religiones se enfrentan a unos desafíos muy grandes provenientes de la secularización y del laicismo militante. Como fruto de la secularización se van dando fenómenos como la separación entre ciencia y religión, la reducción paulatina de la práctica cultual, la no consideración de una religión como religión estatal y la pérdida de relevancia de las instituciones religiosas. Esto se puede ver estadísticamente en los países industrializados de Occidente y algunos lo denominan ya como la agonía de la Iglesia católica.

El laicismo, por su parte, cuando es militante desea ver la religión como un vestigio del pasado, como una manera de pensar mágica o supersticiosa, que debe desaparecer en una sociedad científica e ilustrada. No sólo critica a la religión y sus adherentes, sino que busca de manera activa su desaparición de la vida pública de todos los pueblos. Casi que se llega a un ateísmo de estado en el cual el programa antirreligioso es política institucional y actitud mental generalizada.

Dos de las respuestas más comunes a estos desafíos por parte de las religiones son refugiarse en el ghetto como una protección de unos pocos elegidos que practican su fe en forma vergonzante, o emprender una nueva cruzada contra los infieles en forma fundamentalista y hasta terrorista.

En el primer caso se ha dicho que el futuro de las religiones es el ghetto. El ghetto parece una solución aceptable para aquellos que desean vivir su religión en paz sin estar sujetos a las críticas que vienen del contexto circundante. Un ghetto donde los valores se vuelven rígidos como reliquias de un pasado ya ido. Otros plantean la solución del ghetto como un resultado de la desaparición de la religión en el siglo XXI. «En el siglo XXI, los creyentes religiosos solo se encontrarán en pequeñas sectas, agrupados juntos para resistir una cultura secular global» (Berger, 1968).

La idea de ghetto puede entenderse de tres maneras:

-Una subcultura rígida dentro de una cultura secular, aislada de los hombres del común. Conservar la verdad en un mundo de pecado, alcanzar la salvación sin contacto con el mundo. Es una eclesiología de sociedad perfecta donde la Iglesia no necesita del mundo, una situación muy semejante a la vivida por la Iglesia en el siglo XIX y juzgando como pecaminosa toda actitud o comportamiento que dé razón a la modernidad. 
-Un retiro último para los últimos creyentes, un refugio antes del final. Un refugio para una religión que se acabó y que espera el final con paciencia. La religión ha llegado a su final, quizá su recuerdo quede en museos y obras arquitectónicas que el estado puede mantener como patrimonio cultural. Hay una corriente laicista que quiere arrinconar a la iglesia en los márgenes del grupo social (laicismo militante o fundamentalismo laico).

-Un último baluarte desde donde se pueda defender la fe. Mentalidad de ghetto: somos pocos pero los únicos en la verdad, somos los últimos pero podemos reconquistar el mundo. Esta tercera posición emparenta con los que tienen mentalidad de cruzada. Como también con los apocalípticos que esperan un juicio divino por medio del fuego y el renacer de una nueva era.

En otras palabras, el ghetto es el futuro. Los grupos que rechazan las normas sin esperanza del mundo moderno poblarán el mundo. Muchos de sus descendientes se adherirán a su fe y el camino pasado de moda evangelizará misioneramente. Las familias grandes asumirán de nuevo a los ancianos y las parroquias vacías se llenarán otra vez del sonido del cántico en latín; y el colegio católico ortodoxo sustituirá al Colegio de Boston y al de Georgetown como autoridad moral entre los católicos (Zmirak, 2010).

Ya Escrivá de Balaguer se oponía a una visión de la iglesia alejada del mundo, entendida como sólo vida espiritual sin ninguna relación con la sociedad en general:

Cuando se ven las cosas de este modo, el templo se convierte en el lugar por antonomasia de la vida cristiana; y ser cristiano es, entonces, ir al templo, participar en sagradas ceremonias, incrustarse en una sociología eclesiástica, en una especie de mundo segregado, que se presenta a sí mismo como la antesala del cielo, mientras el mundo común recorre su propio camino. La doctrina del Cristianismo, la vida de la gracia, pasarían, pues, como rozando el ajetreado avanzar de la historia humana, pero sin encontrarse con él (Escrivá, 1967).

Otros con una visión integrista plantean la cruzada. Estos sugieren que hay que volver a los tiempos de la Vendée, de los Cristeros, de los pueblos eslavos levantados contra el comunismo, de la guerra civil española, o de los conservadores latinoamericanos que en el siglo XIX iban a la guerra contra los liberales con escapularios y rosarios. Hay grupos europeos que sugieren dedicar dinero y esfuerzos para convertir a 
los musulmanes a los valores cristianos. Defender la civilización occidental cristiana ha sido idea común dentro de la llamada Ideología de la Seguridad Nacional en Latinoamérica. Es el tiempo de volver a las Cruzadas. Grupos como la Militia Christi se entienden como un estilo particular de vida cristiano como soldados de Cristo, valientes, aguerridos, apasionados, como un ejército en pie de lucha dispuestos a defender el reino de Dios aún con la propia vida bajo la protección del arcángel San Miguel.

Pero en otras religiones también se da el espíritu de cruzada cuando se trata de mantener la teocracia en estados modernos, cuando se recurre al terrorismo o cuando se trata de mantener la norma religiosa como ley constitucional de los estados.

Igualmente, hay una actitud fundamentalista laicista que quiere enviar las religiones al ghetto pues las considera supersticiones, irracionalidades, dominio ideológico y corporal, estorbo para la modernización o freno del progreso de la humanidad. Esta actitud está generando no la ghettización de las religiones, sino el despertar de un fundamentalismo religioso con intenciones políticas cuando no terroristas. Es tan peligroso el fundamentalismo laico como el fundamentalismo religioso.

\section{El proceso del pluralismo y la laicidad}

La época de la Ilustración es la que inicia la preocupación por el pluralismo, la laicidad y la multiculturalidad, aunque su origen propiamente se da como la gradual aceptación de la tolerancia como consecuencia de las guerras de religión en el siglo XVI. El Edicto de Nantes de 13 de abril de 1598 es inicio del reconocimiento de la libertad religiosa y del principio de unidad nacional desvinculado del principio de unidad religiosa. Esa progresiva secularización del poder político permitirá el reconocimiento de la libertad de conciencia pues los principios de laicidad y libertad de conciencia se reclaman y se complementan. Esencial en el progresivo reconocimiento de la libertad religiosa se encuentra la Reforma protestante con sus doctrinas y pluralidad, especialmente con su enseñanza de la conciencia individual, el libre examen y la decisión personal.

Antes se daba pluralidad (hecho sociológico) pero no pluralismo en su amplia acepción como ordenamiento legal, reconocimiento civil y actitud positiva ante el hecho de la existencia y convivencia de varias y distintas religiones o confesiones religiosas dentro de un clima de respeto a la conciencia y a la libertad individuales. Se puede decir que en toda 
sociedad ha habido pluralidad religiosa pero casi siempre con una religión dominante $\mathrm{o}$ estatal $\mathrm{y}$ otras religiones dominadas $\mathrm{O}$ maltrechamente permitidas.

En cuanto empieza a hablarse de tolerancia se va dando paso al pluralismo (que supera la mera pluralidad), el multiculturalismo (que va más allá de la multiculturalidad), la laicidad (que no es laicismo) y luego al ecumenismo tanto dentro de las iglesias cristianas como al diálogo interreligioso más universal y amplio.

El término laicidad y su aplicación por parte de algunos gobiernos, llevó también al debate sobre las relaciones Iglesia-Estado en Europa y a pensar que el Estado debía ser independiente de las religiones. La palabra laicidad tiene origen en Francia a fines del siglo XIX y está relacionada con el fenómeno y problema de la enseñanza laica, es decir, enseñanza no confesional. La aplicación del término laico al Estado viene a definirlo como neutral ante las confesiones religiosas y tolerante con todas ellas. Para el logro del principio de separación entre Iglesia-Estado será esencial el reconocimiento de la libertad religiosa. Esto motiva a situar el punto de partida del estudio del origen del Estado laico en la secularización del poder político y su configuración como Estado Moderno, por una parte, y en el reconocimiento de la libertad religiosa, por otra, factores puestos en marcha por la Revolución francesa.

Pluralismo, tolerancia, multiculturalismo, laicidad y ecumenismo, son conceptos que se fueron formando lentamente, y con circunstancias propias de cada región, desde la alta edad media. Uno de los iniciadores fue Marsilio de Padua que en su obra Defensor pacis (1324) defiende que la Iglesia no debe hacer o tener acciones temporales y proclama así cierta laicidad del Estado separado de la Iglesia; realiza un ataque al poder temporal de los papas que servirá posteriormente al luteranismo en su crítica a Roma. Se proclama la separación entre el poder temporal y espiritual. Santo Tomás de Aquino acepta que la Iglesia tenga cierto poder temporal para cumplir su misión, teoría que fue combatida por las órdenes mendicantes, especialmente, los franciscanos. Marsilio no aceptaba la doctrina tomista e insistía en el poder del príncipe en el orden material, poder que tiene como límites al mismo pueblo. La iglesia debía dedicarse a predicar el evangelio, promover la moral privada y contribuír al sostenimiento del orden político. En este sentido, Marsilio aparece como reformador de la Iglesia que debía dedicarse a lo espiritual y bajo la autoridad del príncipe. La Iglesia tiene una función espiritual dentro del Estado pero no lo gobierna. Cristo «se quiso excluir a sí mismo y a sus apóstoles del oficio de gobernar o de la jurisdicción contenciosa, o régimen o juicio coactivo cualquiera en este mundo» (Marsilio de Padua, 1989: 4; Godoy, 2003). 
Jean Bodin (s. XVI) propone la soberanía como una propiedad del Estado que no debe inmiscuirse en los problemas de la verdad de los dogmas. En Heptaplomeres, Bodin presenta una discusión entre un católico, un luterano, un calvinista, un hebreo, un mahometano, un pagano y un adepto a la religión natural, para proponer el tema de la tolerancia en términos de la universalidad de la razón (Bodin, 1970). Juan Althusius aceptó en su Politica Methodice Digesta (1603) que la tolerancia resulta una norma indispensable en política: «los que están en el error en materia de religión no deben ser corregidos por la fuerza externa ni por las armas humanas, sino por las armas del Espíritu Santo... Y si la palabra de Dios no les convence, mucho menos les convencerán las amenazas del gobernante o los castigos que éste les inflija» (Kamen, 1967: 219).

En su Tractatus Theologico-Politicus (1670), Baruch Spinoza afirma que la libertad del individuo está a la base de la constitución del Estado y que «debía ser lícito que cada uno pensase aquello que quisiera y que cada uno dijese aquello que piensa [...]. Es un derecho natural de la persona el juzgar e interpretar la religión, ya que la religión entra dentro de los asuntos propios de cada individuo [...] Hay que conceder necesariamente la libertad de opinión y así se podrá proveer a la paz y amistad necesaria para que se pueda vivir, aunque las diferencias de criterios entre unos y otros sean manifiestas y notorias» (Kamen, 1967: 220).

En la línea de Spinoza, Samuel Pufendorf en De Habitu Religionis Christianae ad Vitam Civilem (1687) insiste en que el contrato original que establece una sociedad no puede exigir ninguna renuncia a las creencias religiosas personales y que el sujeto debe vivir en «estado de socialidad pacífica» con los demás. Pudendorf afirma que solo conviene la intervención del gobierno cuando con el pretexto religioso se altere la paz, se organicen levantamientos o se gesten traiciones. En esos casos los poderes civiles podrán actuar y castigar. No corresponde al príncipe perseguir a sus súbditos por el solo hecho de diferir en materia de religión (Kamen, 1967: 222). John Locke, autor de la Epistola de Tolerancia ad Clarissimun Virum (1689), así como de las otras tres cartas sobre la tolerancia (1689, 1690 y 1692), introduce el principio de la libertad religiosa, y es uno de los primeros promotores de la libertad civil como parte consustancial del espíritu social. La importancia especial de Locke radica en que considera que el principio de la tolerancia constituye «un punto de encuentro» entre las tareas y los intereses que caracterizan, respectivamente, a la Iglesia y al Estado. Desde esta perspectiva, Locke es el más importante eslabón teórico entre el pensamiento de la Ilustración y el liberal. 
Anteriormente, el Estado era considerado un fenómeno religioso y la religión un fenómeno social. Desde la conversión al cristianismo del rey Clodoveo, en 496, se inicia la intervención real en los asuntos de la Iglesia católica y viceversa que tendrá su mayor expresión en la proclamación de Carlomagno como emperador en el año 800. Francia tuvo en las guerras de religión el hecho social que marca, de manera conflictiva, el inicio de la libertad religiosa. Las guerras de religión comenzaron en 1562 y terminaron con el Edicto de Nantes en 1598. La religión fue la causa principal del conflicto. «Une foi, une loi, un roi» es la expresión sencilla de la causa. El Estado, la sociedad y la religión estaban unidos en la mente y la experiencia del pueblo en general. No había distinción entre ellos pues la religión había formado parte del consenso social por más de un milenio. Desde Clodoveo, la corona francesa estaba ligada a la Iglesia: ésta le daba legitimidad y santidad, y aquella la protegía militar y civilmente. Una sola fe era esencial para el orden social pues si no existía un solo Dios que sostuviera el orden natural, todo se vendría al suelo. Las herejías eran una traición al estado, pues corrompían las bases del consenso social. Toda religión nueva se veía como un atentado contra la nación. Sin el cristianismo católico, vendría la anarquía y la división. Las ideas protestantes, en cambio, eran bastante novedosas: hay que obedecer al rey pero el pueblo lo puede deponer si ataca a la Iglesia, y aún más, se podía elegir al rey por parte del pueblo y el rey debía gobernar con el consenso del mismo pueblo. Los cien o más días de fiesta de los católicos deberían aprovecharse para el comercio. (Hay que notar que los hugonotes eran principalmente urbanos y comerciantes). La participación de las mujeres en los servicios religiosos, la lectura de la Biblia por parte de todas las personas, las mujeres cantando en las asambleas, eran cosas imposibles de aceptar por parte de los católicos. Estos creían que permitir la herejía era mantener una enfermedad dentro del grupo social. Se llegó a excesos de violencia como la Noche de San Bartolomé, el 23 de agosto de 1572, cuando la misma población portando cruces blancas en sus sombreros, colaboró en la masacre de los hugonotes, que se extendió durante varios meses por todo el país.

El Edicto de Nantes de 13 de abril de 1598, es el inicio del reconocimiento de la libertad religiosa y del principio de unidad nacional desvinculado del principio de unidad religiosa. Esa progresiva secularización del poder político permitirá el reconocimiento de la libertad de conciencia, pues los principios de laicidad y libertad de conciencia se reclaman y se complementan. Esencial en el progresivo reconocimiento de la libertad religiosa se encuentra la Reforma protestante con sus doctrinas y pluralidad, especialmente con su 
enseñanza de la conciencia individual, el libre examen y la decisión personal.

Por su parte, la Iglesia católica, desde el Papa Gelasio (492-496), venía formando la doctrina de la superioridad del Pontífice, pues lo temporal debe estar supeditado a lo espiritual. Una expresión madura de la supremacía pontificia se da en el Dictatus Papae (1075) del Papa Gregorio VII (Henderson, 1910: 366-367). Este se presenta como un emperador integral con todos los poderes. Bonifacio VIII va más allá cuando en la Bula Unam Sanctam del 18 de Noviembre de 1302 postula la necesidad de obedecer al Papa para alcanzar la salvación: «Además, declaramos, proclamamos, definimos que es absolutamente necesario para la salvación que toda criatura humana esté sometida al Romano Pontífice» (Denzinger, 1963: n. 468-469). Esta doctrina de la supremacía pontificia coloca al Papa y a la Iglesia católica, como la Verdad absoluta de Dios en el mundo, y todo tendrá legitimidad si está sancionado por la jerarquía eclesiástica. Lo que sea distinto o diferente, será obra del pecado y romperá la unidad de la humanidad. El error debe ser extirpado, pues prima la verdad sobre la persona, y la salvación eterna sobre la vida del sujeto.

El régimen eclesiástico es el que legitima el régimen temporal como lo expresa claramente el Papa Inocencio III, en la carta Sicut universitatis conditor (1198):

El Creador del Universo colocó dos grandes luminarias en el cielo; la más grande para regir el día, la menor para regir la noche. Del mismo modo, para el firmamento de la iglesia Universal, que se dice como del cielo. El nombró dos grandes dignidades; la más grande debe regir sobre las almas (es decir, los días), la menor para regir los cuerpos (es decir, las noches). Estas dignidades son la autoridad pontificia y el poder real. Además, la luna deriva su luz del sol, y es, en verdad, inferior al sol en tamaño y cualidad... De la misma manera, el poder real deriva su dignidad de la autoridad pontificia (Denzinger, 1963: n. 767).

Queda claro que los derechos naturales de los pueblos se legitiman únicamente desde el derecho divino administrado por la Iglesia. El papa es amo y señor del universo desde la Plenitudo potestatis. Pero toda esa doctrina es contestada desde la Ilustración y la modernidad con su planteamiento sobre la sociedad plural y legal.

La Ilustración implicará la autonomía e independencia del poder político y del derecho de la tutela de la fe religiosa, y en consecuencia el reconocimiento de la libertad de conciencia y de la imposibilidad de que el Estado intervenga en los asuntos espirituales. Son importantes para 
ayudar al reconocimiento de la libertad religiosa, las aportaciones de autores como Pierre Bayle, en su obra de 1686, Commentaire philosophique sur ces paroles de Jésus-Christ "Contrains-les d'entrer》 (Comentario filosófico de las palabras de Jesucristo "Obligalos a entran») donde expresaba que la coacción en la esfera religiosa era inmoral y suponía un atentado a la dignidad humana; donde reivindica la libertad de conciencia, también para ateos y seguidores de religiones no cristianas, y no sólo como principio moral, sino como un precepto de la razón (Bahr, 2001: 59-80). Voltaire, en su Tratado de la Tolerancia (1773), exponía que el gobierno no debía estar al servicio de la Iglesia y pedía el reconocimiento de la libertad de pensamiento. Su alegato contra la intolerancia es de gran actualidad:

El derecho humano no puede estar basado en ningún caso más que sobre este derecho natural; y el gran principio, el principio universal de uno y otro es, en toda la tierra: 'No hagas lo que no quisieras que te hagan'. No se comprende, por lo tanto, según tal principio, que un hombre pueda decir a otro: 'Cree lo que yo creo y lo que no puedes creer, o perecerás'. El derecho de la intolerancia es, por lo tanto, absurdo y bárbaro: es el derecho de los tigres, y es mucho más horrible, porque los tigres sólo matan para comer, y nosotros nos hemos exterminado por unos párrafos (Voltaire, 1773: 67).

En el Contrato social (1820), Jean Jacques Rousseau, defendía que todos pueden tener las opiniones que quieran sin que corresponda al soberano conocerlas, porque no tiene competencia en las cosas sobrenaturales:

Los vasallos no deben dar cuenta al soberano de sus opiniones, sino en cuanto ellas importan a la comunidad. Aunque importa al Estado que cada ciudadano tenga una religión que le haga amar sus deberes; pero los dogmas de esta religión no interesan ni al estado ni a sus miembros, sino en cuanto dichos dogmas se relacionan a la moral o a los deberes que el que la profesa, está obligado a cumplir para con los otros. Por lo demás, cada uno puede tener las opiniones que le acomoden y sin que pertenezca al soberano entender sobre esto: porque como no tiene competencia en el otro mundo, sea la que quiera la suerte de los vasallos en la vida venidera, esto no es asunto del soberano, con tal que en la presente sean buenos ciudadanos (Rousseau, 1820: 231).

En cuanto a la separación entre Estado y religión, el aporte de Condorcet es importante. Propone separar, en un ambiente de razón, tolerancia y humanidad, el elemento eclesiástico de los asuntos públicos y de la educación, dando sí a las confesiones religiosas plena libertad, pues 
el poder público no tiene derecho de unir enseñanza de la religión con enseñanza de la moral. La formación religiosa no puede hacer parte de la instrucción común, pues lo religioso es elección de la conciencia independiente y la autoridad no puede preferir una religión a la otra (Condorcet, 1847: 204).

Las democracias modernas están condicionadas por el descubrimiento de que el disenso y la diversidad, no son incompatibles con el orden social y el bienestar del cuerpo político. La génesis ideal de nuestras democracias se halla en el principio de que la diferencia, no la uniformidad, es el germen y el alimento de los estados, un punto de vista que se extendió a continuación de la Reforma, después del siglo XVII.

$\mathrm{Al}$ respecto, Inmanuel Kant, en cuanto al ámbito de las creencias, es muy claro:

Si no pretende otra cosa (el gobernante), sino que todo mejoramiento real o presunto sea compatible con el orden ciudadano, no podrá menos de permitir a sus súbditos que dispongan por sí mismos en aquello que crean necesario para la salvación de sus almas; porque no es ésta cuestión que le importe, y sí la de evitar que unos a otros se impidan con violencia buscar aquella salvación por el libre uso de todas sus potencias. Y hará agravio a la majestad de su persona si en ello se mezcla hasta el punto de someter a su inspección gubernamental aquellos escritos en los que sus súbditos tratan de decantar sus creencias, ya sea porque estime su propia opinión como la mejor, en cuyo caso se expone al reproche: Caesar non est supra grammaticos, ya porque rebaje a tal grado su poder soberano que ampare dentro de su Estado el despotismo espiritual de algunos tiranos contra el resto de sus súbditos (Kant, 2006: 33-34).

Con el avance de la Ilustración se llega a considerar que cada individuo es libre de escoger y practicar su religión, y que ésta se reduce al ámbito de lo privado, sin consecuencias públicas o sociales. En la Ilustración se tiene una definición de religión como creencia personal que se expresa en culto colectivo, de tal manera que constituye una comunidad social, pero que no tiene por qué controlar al Estado ni por qué ser de tipo étnico o sociológico. Es una comunidad de la que se puede salir o a la que se puede entrar.

Así va surgiendo el concepto de pluralismo que inicialmente era una doctrina acerca de la plenitud de posibles puntos de vista o de ideologías combinada con la invitación a adoptar el punto de vista de un ciudadano del mundo por encima de visiones particularistas. Hoy se refiere a que el mundo puede ser interpretado y vivido en diversas formas. En ética y sociología se trata de que la sociedad moderna no está ya más fundamentada en normas y doctrinas trascendentes o confesionales y 
que toda ética está sujeta a cambio y discurso racional. Se considera el pluralismo como la convergencia cosmovisiones con la invitación a adoptar una cosmovisión universal: la del ciudadano global.

Partiendo de estas perspectivas, en la actualidad los problemas teóricos y prácticos siguen presentes: ¿Cómo se entienden las culturas religiosas? ¿Puede la religión separarse de la vida social? ¿Es la religión una ONG en la sociedad democrática? ¿Se pueden separar cultura e Islam? ¿Tiene la religión un papel en la sociedad civil? ¿Debe relegarse lo religioso sólo a la privacidad? ¿Se puede ser democrático y creyente? ¿Cómo se compagina religión (como hecho social) y política?

\section{Dos modelos de laicidad}

Se hace importante recalcar que el pluralismo constructivo reconoce la diferencia para promover armonía e interacción entre personas, grupos y culturas. Este pluralismo no es restrictivo, agresivo o excluyente sino una búsqueda de la unidad en la diversidad. Pero la laicidad ilustrada llevó en algunas partes a una actitud antirreligiosa y claramente fanática. Laicidad no significa necesariamente persecución, y en este sentido hay que «deslaicizar la laicidad», de modo que ésta no se convierta en una pararreligión, sino que sea la aceptación serena de las diferentes formas religiosas y la aceptación de su aporte al todo social. Un estado laico no es antirreligioso o anticlerical, sino un estado que respeta a todas las formas religiosas, sin aceptar ninguna como oficial o privilegiada, pero que al mismo tiempo mantiene una relación amistosa y tolerante con todas ellas. Uno de los temas discutidos hoy es el de «repensar la laicidad», como apertura a una laicidad positiva, distinta al separatismo militante. Este, al confrontarse con la multiculturalidad que exige el respeto a las diversas culturas con sus manifestaciones, se muestra ineficaz para dar respuestas respetuosas a los anhelos de identidad y a los deseos de participación. Una laicidad intransigente ahoga la libertad, la iniciativa y la responsabilidad social de los diversos grupos religiosos, que pueden ser constructivos en su medio.

Puede haber diversos modelos en la relación Iglesia-Estado. El hecho laico no significa rechazo total de la religión (laicidad activa) sino el reconocimiento de posibles y diversas formas de relación según el caso histórico y cultural de la nación. Puede darse el modelo de una religión nacional (Grecia, Portugal, Dinamarca), o el reconocimiento de dos religiones nacionales (Finlandia: iglesia luterana y ortodoxa; Inglaterra: iglesia de Inglaterra e iglesia de Escocia). Puede ser el modelo de «no reconocimiento de ninguna religión»(EE.UU, Holanda, Francia), o el 
modelo de reconocimiento múltiple (Italia, Bélgica, España, Austria, Alemania). Es laicidad positiva en lugar de laicidad activa.

El modelo francés de laicidad proviene del enfrentamiento entre dos formas de ver la historia de Francia, dos cosmovisiones, que son la Francia católica y la herencia de la Revolución francesa de 1789. Se da una lucha sin reconciliación donde prima la pasión sobre la razón y que sólo se calmará en 1945 cuando los obispos aceptan la laicidad, pero que en los últimos años renace frente a casos particulares como la inmigración musulmana.

El combate que se emprende entonces tiene como objetivo el poder, político y cultural, en la nación; es asimismo el choque entre dos sistemas ideológicos absolutamente incompatibles. No están en cuestión ni la creencia en Dios ni la existencia de las Iglesias - los ateos y anticristianos militantes, minoritarios, ejercen su influencia sin controlar durante mucho tiempo la acción gubernamental- sino el lugar de la religión y de sus organizaciones en la vida nacional, regulada en adelante por el espíritu democrático... El partido republicano en el poder erige en veinticinco años una legislación que excluye, en primer lugar, a la religión de la escuela pública, que, después, elimina las congregaciones religiosas, y que, finalmente, rompe la alianza concordataria: estas medidas caracterizarán el régimen francés de laicidad» (Comte, 1998: 21ss).

En cambio, en Norteamérica el proceso es diferente. En ésta la religión va a tener una gran importancia en la fundación del país y en la constitución de la democracia. Tocqueville al analizarlo, dice que hay una doble raíz en la nación: la bíblica y la filosófica, que pueden convivir gracias al principio ilustrado revolucionario de separación de Iglesia y Estado, y eso explica la permanencia de la democracia. La convivencia del espíritu religioso junto al espíritu libertario era el síntoma de algo muy profundo humanamente como es el deseo de armonizar cielo y tierra. Si el hombre se aleja de su fe religiosa puede violentar su naturaleza humana, social y familiar. Norteamérica seguirá esta línea (Tocqueville, 1963). La laicidad norteamericana es diferenciación estructural de los ámbitos seculares y los religiosos, sin que implique privatización de la religión o el envío de ella al cuarto de cosas inútiles. En el fondo, la sociedad americana es profundamente religiosa. No es un laicismo anticlerical o antirreligioso como el francés. Las intervenciones del episcopado en la plaza pública con sus cartas sobre la guerra, el sistema económico o el aborto son muestra de cómo se proclama públicamente una posición religiosa sin pretender imponer una moral particular a toda la nación. Se puede intervenir en la vida pública desde la convicción de que las propias tradiciones normativas son fuentes necesarias para generar los recursos morales que la sociedad necesita, 
simplemente sometiendo dichas tradiciones a las reglas de juego del debate democrático público y abierto y disponiéndose a dinamizar dicho debate. Pero hay que estar dispuesto, para ello, a renunciar a modelos propios de «Iglesia oficial» y a una movilización de masas que pretendan conquistar parcelas de poder.

El modelo norteamericano fue el que influyó en las discusiones del Concilio Vaticano II bajo la influencia de John Courtney Murray. Dice que el gobierno iría más allá de sus finalidades si juzga sobre la verdad o falsedad de una religión, si obliga a los ciudadanos en materia teológica o si declara a una religión como la religión oficial del Estado. Concluye diciendo que la verdadera tradición en esta materia, de separación IglesiaEstado y de libertad religiosa, fue preservada en el sistema constitucional americano (Courtney, 1963: 706).

El modelo del pluralismo religioso tal como lo practica la laicidad francesa es un modelo conflictivo, pues se entiende como el Estado contra las Iglesias. El modelo norteamericano es más positivo: las iglesias independientes del Estado. La perspectiva francesa va acompañada de lo que Hervieu-Léger llama «un deseo más o menos claramente expresado de arrancar las conciencias de la influencia de representaciones juzgadas radicalmente contradictorias con la razón y la autonomía: un deseo que nutre la desconfianza visceral (aunque raramente explicitada) frente a la creencia religiosa como tal» (Hervieu-Léger, 2001: 22). Es un laicismo agresivo con raíces en la Ilustración y en la Revolución francesa en las que se da la búsqueda de la modernidad como lucha contra el monopolio simbólico y las influencias políticas de la iglesia católica. En este sentido, a juicio de la misma autora, la separación a la francesa fue elaborada para constreñir a la iglesia a limitarse a sus objetivos espirituales, aún si no se la podía recluír en las sacristías, pensando en proteger al estado contra la posible expansión de la iglesia, mientras que en Estados Unidos la separación busca garantizar la libertad de las confesiones religiosas de cualquier invasión del Estado (Hervieu-Léger, 2001: 31). Al respecto, en los países latinoamericanos que lograron su independencia bajo la égida intelectual francesa, hubo grandes conflictos entre las dos posiciones: conservadores tradicionalistas y liberales modernizantes.

\section{La laicidad en la doctrina de la iglesia católica hoy}

Durante el siglo XIX, y en la primera mitad del siglo XX, la Iglesia siguió condenando el laicismo y mantuvo una actitud crítica frente a la modernidad, tal como se expresaba en el Syllabus, de 1864, del Papa Pío IX. Por eso se dice que la palabra «laicidad» aparece tardiamente en el 
lenguaje teológico. Ni en el Dictionnaire de Théologie Catholique, ni en la enciclopedia Sacramentum Mundi aparece el término laicidad. En la enciclopedia Cristianismo editada en Madrid en el 2009 ya hay una referencia teológica a la laicidad. El trabajo de Giuseppe della Torre denominado La città sul monte: contributo a una teoria canonistica sulle relarioni tra chiesa e communità política (Roma, 2002), es de tipo canónico y jurídico pero no teológico. En el ámbito popular la idea difusa era que la Iglesia debía mantener su posición tradicional y que la palabra tolerancia no hacía parte del vocabulario católico. Sin embargo, ya se venían gestando por debajo las reflexiones que permitirían una renovación no sólo del término sino de las mismas concepciones eclesiológicas y de las relaciones Iglesia-Estado.

La palabra «laicidad» comienza a perder su sentido agresivo y se crea el término «laicismo» como complementario para expresar una posición política antirreligiosa $o$ anticlerical. Influyen en este cambio las reflexiones sobre el laicado hechas por los teólogos y filósofos, tales como Maritain, Congar, Schillebeeckx, von Baltasar y Rahner. Sobre todo Maritain tiene una reflexión sobre la substantividad de lo profano y de su independencia del orden religioso. Sin abandonar los principios católicos, habla de aplicarlos según el espíritu de la época moderna:

No se pretende de ninguna manera por ésto que la verdad y el error tengan los mismos derechos, ni que las diversas confesiones religiosas tengan, por sí y en sí mismas, los mismos derechos, ni que 'el progreso del tiempo' obligue a considerar como abolidos los derechos superiores de la Iglesia, ni que haya que rechazar en principio toda estructura del Estado en que la religión católica tenga una situación jurídica privilegiada y condenar así lo que ha existido durante siglos de civilización cristiana! Se dice únicamente que, en las condiciones históricas de nuestra edad, es ventajoso para el bien común temporal y también para la Iglesia que ésta consienta en no hacer uso del derecho superior que le pertenece y en aceptar para los suyos una condición jurídica de acuerdo con la igualdad de derechos entre los ciudadanos que el Estado reconoce en su propia esfera temporal (Maritain, 1948: 259).

Las tesis de estos escritores van calando en la mentalidad eclesial e influirán decisivamente en el Concilio Vaticano II. Este introdujo cambios radicales en la concepción de la Iglesia especialmente en el concepto de ella como «sociedad perfecta» que venía del Concilio Vaticano I. La Iglesia no está llamada a gestionar el ámbito temporal puesto que «en razón de su función y competencia, no se confunde, de ningún modo con la comunidad política y no está vinculada a ningún sistema político» (Gaudium et spes, 76). Pero todos deben trabajar por el 
bien común. «La comunidad política y la iglesia (...) aunque por diverso título, están al servicio de la vocación personal y social del hombre. Este servicio lo realizarán con tanta mayor eficacia, para bien de todos, cuanto más sana y mejor sea la cooperación entre ellas» (Gaudium et spes, 76).

Se nota perfectamente el influjo de Maritain: un mundo más humano, más desarrollado, más científico, más participativo, construído a plena conciencia y con la participación de todos los hombres. Un mundo que tiene todo su valor (no simplemente un medio), sin tampoco pensar que la construcción del mundo es un fin absoluto. También el Concilio dibuja la figura del laico (Decretos Apostolicam Actuositatem y Lumen Gentium). Laicos son «todos los fieles cristianos, a excepción de los miembros que han recibido un orden sagrado y los que están en un estado religioso reconocido por la Iglesia, es decir, los fieles cristianos que, por estar incorporados a Cristo mediante el bautismo, constituidos en Pueblo de Dios y hechos partícipes a su manera de la función sacerdotal, profética y real de Cristo, ejercen, en la parte que les toca, la misión de todo el pueblo cristiano en la iglesia y en el mundo» (Lumen gentium, 31) y a ellos les corresponde organizar los asuntos temporales.

Insiste también el Concilio en el derecho a la libertad religiosa como libertad de coacción por parte de grupos sociales o de cualquier poder humano, de tal manera que ni se obligue a nadie a obrar contra su conciencia, ni se le impida que actúe conforme a ella en privado y en público, solo o asociado con otros, dentro de los límites debidos. (Dignitatis Humanae, 2).

En este contexto, es fundamental el aporte del teólogo John Courtney Murray que colaboró en la redacción de los decretos sobre la libertad religiosa y sobre el ecumenismo. Importantísimo fue su artículo On Religious Liberty (Courtney, 1963: 704-706). En él parte de dos premisas: todo hombre tiene por naturaleza, el derecho al libre ejercicio de su religión en la sociedad, de acuerdo a los dictados de su conciencia personal; y el reconocimiento de este derecho recae especialmente en el Estado, lo mismo que su respecto y promoción de su libre ejercicio. Las razones para que la iglesia proclame esta doctrina son cuatro:

-En las pasadas generaciones esta doctrina de la libertad religiosa ha sido ya clarificada por la reflexión teológica.

-La iglesia debe asumir un patronato universal de la dignidad de la persona humana y de sus libertades especialmente en un momento en el cual hay tiranías totalitarias.

-Estamos en una sociedad pluralista religiosamente hablando y los hombres deben vivir juntos y en paz en condiciones de amistad cívica. 
-Estamos en una época en la que ha nacido una gran esperanza ecuménica (Courtney, 1963: 704).

La decisión en favor o en contra de Dios es una decisión personal. Por eso, ningún hombre, y menos un cristiano, debe ejercer ninguna clase de coerción física, moral o legal sobre otro hombre (Courtney, 1963: 705). Ese derecho ha de regularse bien de tal manera que no quede sujeto a «razones de estado» o a una velada invocación a los derechos de la mayoría (Courtney, 1963: 706).

El laicismo casi fundamentalista pone en peligro esta libertad religiosa. La libertad religiosa exige una laicidad no agresiva sino justa. Así, el Estado no controla las religiones sino que les deja espacio para que sean constructoras de vida social, de modo que laicismo no es laicidad. En palabras de Juan Pablo II en el discurso al cuerpo diplomático acreditado ante la Santa Sede, del 12 de enero de 2004:

La laicidad no es el laicismo! No es otra cosa que el respeto de todas las creencias por parte del Estado, que asegura el libre ejercicio de las actividades de culto, espirituales, culturales y caritativas de las comunidades de creyentes. En una sociedad pluralista, la laicidad es un lugar de comunicación entre las diferentes tradiciones espirituales y la nación. Las relaciones Iglesia-Estado pueden y deben dar lugar a un diálogo respetuoso, que transmita experiencias y valores fecundos para el porvenir de una nación. Un sano diálogo entre el Estado y las Iglesias - que no son corrientes, sino socios- puede sin duda favorecer el desarrollo integral de la persona y la armonía de la sociedad.

La Doctrina Social de la Iglesia reconoce el principio de laicidad que recuerda la necesidad de una justa separación de poderes retomando así la legítima y sana laicidad de la que hablaba Pío XII (1958) para plantear que no se trata de un tipo de laicismo ideológico o separación hostil entre las instituciones civiles y las confesiones religiosas sino para responder al nuevo marco pluriétnico, multicultural y multiconfesional. Y en el n. 28 de la Encíclica Deus Caritas est, el Papa Benedicto XVI reafirma la posición católica sobre la laicidad: «El Estado no puede imponer la religión, pero tiene que garantizar su libertad y la paz entre los seguidores de las diversas religiones».

Finalmente, urge la construcción de una laicidad cooperante y respetuosa, dejando de lado el laicismo trasnochado, iluminista, segregante. Por eso, tal vez sea mejor pensar en la laicidad de estilo norteamericano que en la de tipo francés, pero aplicándola creativamente a las situaciones nacionales, donde después de los enfrentamientos, se 
aprende a convivir creativa y pacíficamente, aunque sea a partir de la experiencia de la exclusión, la violencia y la segregación.

\section{Pluralismo}

Hay varios niveles de inteligencia del pluralismo en la sociedad:

Nivel Amplio o Macro. La autoridad civil reconoce legalmente la pluralidad. Esto es lo que se denomina la tolerancia religiosa y que queda enmarcada en el campo de lo jurídico. El Estado es laico y respeta las religiones, pero no acepta el dominio de alguna de ellas. Todas son reconocidas siempre que cumplan unos requisitos mínimos de orden legal. Es el nivel de la afirmación legal. Hay una igualdad de todas las confesiones religiosas ante el Estado, siempre y cuando no vayan contra el contrato social, democráticamente establecido. Pero no es la simple afirmación legal de la pluralidad. Una sociedad plural no es una sociedad pluralista, pues ésta es aquella en la que todos participan y enriquecen desde su punto de vista.

Nivel Medio. Consiste en la aceptación de la multitud de organizaciones religiosas o sea la denominacionalización de la sociedad. Esto se hace por parte del Estado, de la sociedad y se encarna en los valores culturales. La denominacionalización es el fruto de una sociedad en la cual impera la tolerancia de los grupos entre sí y ninguno tiene una relación de privilegio con el estado. La cultura se hace plural en el campo religioso y las diversas creencias coexisten, se respetan, se toleran y contribuyen a la convivencia social. Es el nivel cívico, donde la sociedad civil reconoce la diferencia y vive en la tolerancia. Es la sociedad la que culturalmente se reconoce plural.

Nivel Micro. El individuo como tal puede escoger sus creencias religiosas. Es el derecho a la libertad de religión, que también incluye la libertad de la religión (no tener ninguna religión). Es la expresión máxima de la libertad de cada sujeto que puede tener o no tener creencias religiosas. Es también un punto discutido, pues el individuo no es un ser abstracto sino un ser contextualizado y de ahí vienen los problemas de si debe haber educación religiosa o no, si la familia puede educar en una fe o debe respetar la libre decisión de la persona o si, respetando las culturas, puede haber estados religiosos. Este es el nivel individual donde se deja la tribalización y el sectarismo y se acepta la diferencia y la opción individual. Se comprueba que el conflicto no 
necesariamente es destructivo. El temor al conflicto hizo pensar a Hobbes en una paz bajo el dominio despótico de su Leviathan. Hoy no son pocos los que vuelven al fundamentalismo como seguridad de una verdad única. Una cultura pluralista implica una visión del mundo basada en la creencia de que la diferencia, y no la semejanza, el disenso y no la unanimidad, el cambio y no la inmutabilidad, contribuyen a la buena vida (Riis, 1999: 20ss).

Para que se pueda dar verdadero pluralismo religioso es necesario que se den los tres niveles arriba expuestos. No es sólo la libertad legal, sino también basar esa libertad en el derecho humano a la libertad religiosa. Pero además, debe existir la cultura de la pluralidad como actitud personal o social, de lo contrario, se cae en una tolerancia abstracta que puede llevar al indiferentismo social. Pluralismo que supone perderle el miedo a la diversidad. Esta no es sinónimo de obstáculo a la unidad sino que puede dar origen a un pluralismo constructivo que, respetando las identidades y reconociendo la diferencia, promueva la armoniosa e interactiva colaboración entre personas, grupos y culturas. Es lo que se puede llamar la estética de la diversidad. Así, el pluralismo es el reconocimiento de la multiplicidad en la sociedad como precondición para la elección libre e individual, pero también para la enriquecedora cooperación de cosmovisiones. Ese reconocimiento de la multiplicidad se encarna en una estructura social, pues de lo contrario se cae en la anarquía anómica (cada uno hace lo que quiere), o queda el campo propicio para el monismo, llámese teocracia, Estado absoluto, monopolio cultural, hegemonización. El pluralismo no es simplemente descriptivo de la presencia de múltiples opciones, sino positivo reconocimiento de la pluralidad como una evaluación afirmativa por parte del colectivo. A la realidad empírica de la diversidad religiosa debe corresponder el pluralismo como manera política y cultural de tomar en cuenta la diversidad. A la pluralidad como hecho sociológico debe corresponder el pluralismo como actitud social y cultural. En este campo se reconoce que el pluralismo se inicia en la diversidad, pero ésta sola no constituye el pluralismo, pues se requiere el cultivo del espacio público donde nos encontremos unos con otros en diálogo constructivo... el compromiso activo de cada uno y un nivel de conocimiento de lo religioso público y de diálogo interreligioso» (Eck, 1992).

La contribución de las creencias y religiones se hace en el espacio público civil. Este es distinto al espacio público religioso ocupado por una sola religión que busca imponer su verdad sin importar la diversidad. $\mathrm{Y}$ es también diferente a lo que quieren los modernistas extremos de un 
espacio público vacío sin trazas de creencias en la construcción de lo público. El espacio público civil se construye sobre la base de que la república descansa en ideas, valores, creencias, símbolos... compartidos por los ciudadanos y en cuya construcción las creencias religiosas pueden aportar. Pero este espacio civil rechaza toda formulación final, ortodoxa, sagrada y permanente de lo que fundamenta la convivencia civilizada según los cánones de una sola o determinada confesión.

En consecuencia:

El pluralismo es propio de la modernidad política y cultural.

El pluralismo independiza ciudadanía de religión, y etnia de religión.

El pluralismo convoca a las religiones a la construcción de nación pero no confunde ésta con aquellas.

El pluralismo es actitud personal y valor socio-cultural, además de decisión jurídica y legal.

El pluralismo supone que el individuo, de manera libre y voluntaria, escoge u opta por un estilo de vida religioso, sin presión de su familia, su grupo o el estado.

\section{Conclusión}

En América Latina podemos decir, a manera de conclusión:

No ha habido, ni hay todavía, pluralismo religioso pues se ha avanzado en el campo legal pero no en el socio-cultural. Se presenta el hecho de la pluralidad pero no la actitud del pluralismo. Sin embargo, en el campo legal todavía se carece de un debate sólido sobre lo que es el pluralismo y sobre la posición del estado frente a las creencias en su manifestación sociológica (Iglesias, congregaciones, cultos, movimientos...). Igual ocurre con las culturas: hay multiculturalidad pero no multiculturalismo como convivencia creativa de grupos, etnias y símbolos. Hay una religión mayoritaria que se ha transmitido sociológicamente, que ha sido intolerante y dominadora, pero que puede aportar en el campo de la tolerancia, el diálogo, el sentido comunitario y la construcción de la paz, bajo los parámetros de un nuevo consenso social.

Ni ghetto ni cruzada. El cristiano no considera el mundo como algo ajeno a la Iglesia, y mucho menos a la Iglesia como quien tiene toda la verdad y la autoridad para dirigir el mundo secular, o considerar que los no creyentes son unos «perdidos». Mucho menos pensar que la Iglesia ha de manejar y dirigir todo a través del clero. Esto sería transmitir un sistema de dominio y de poder y no un mensaje de salvación. Lógicamente, abandonar el mundo por defenderse de él o dejarlo 
abandonado al juicio divino, es una posición no católica y sí muy sectaria. Es una posición propia de ciertos creyentes, generalmente de actitud burguesa, aparentemente muy convencidos, para los cuales la idea de ghetto es atractiva pues se creen estar en la búsqueda auténtica del reino de Dios. Siempre habrá tensión entre la fe religiosa y la cultura: quienes reducen la cultura a fe se encierran en un ghetto fuera del cual todo es amenazante; pero quienes separan la fe de la cultura se quedan pensando que la fe es una creencia personal o una superstición tradicional. Un verdadero diálogo entre fe y cultura permite una sinergia entre las dos que produce una mayor humanización de toda persona. No se trata de relativizar el mensaje sino de llevarlo a su fuente originaria, haciendo una teología de la experiencia viva y no una simple logomaquia dogmática.

La Iglesia puede ser hoy como una especie de laboratorio donde se muestra otra manera de hacer sociedad, «otro mundo es posible», siempre y cuando salga de sí misma y acepte vivir en la plaza pública donde se debaten los temas sociales, donde se forma la opinión pública y donde se piensa la convivencia social. Hablar y compartir sin imponer y sin seguridad, pero que se oiga su voz. Esto exige participación en la vida social y pública dando un testimonio en simplicidad y serenidad. Se trata de reconocer que se está en un mundo plural, diverso, competitivo ideológicamente donde la iglesia no se puede replegar sino mostrar su testimonio con pobreza de poder y brillantez de su luz.

Finalmente, se puede decir: ni una Iglesia en un Estado teocrático donde las normas religiosas sean las normas del estado defendidas con las armas, ni una Iglesia ghetto, recluída con miedo y con temor como una contracultura o un grupo raro o esotérico. Más bien, una Iglesia que es luz, lámpara, grupo de profetas asertivos en la sociedad, sin privilegios ni favores pero tampoco con timideces. La Iglesia puede aportar a los fundamentos prepolíticos del Estado y contribuir a su desarrollo en justicia y libertad (Habermas \& Ratzinger, 2008).

Sin embargo, para esto se necesita la sana laicidad:

Expreso aquí mi convicción profunda, anclada en una larga reflexión y en la experiencia de toda una vida. La laicidad no es 'todo al César, nada a Dios', ni siquiera 'todo al hombre, nada a Dios', sino todo a la conciencia y a la libertad de los hombres, llamados a vivir juntos a pesar de todo lo que les separa, opone o divide (Poulat, 2003: 16). 


\section{REFERENCIAS}

-Bahr, F. (2001). El Commentaire philosophique de Pierre Bayle. Dios no quiere que conozcamos con certeza. Tópicos (9), 59-80.

-Berger, P. (1968). A Bleak Outlook is seen for Religion. New York Times, 25 April: 3.

-Bodin, J. (1970). Colloquium heptaplomeres de rerum sublimium arcanis abditis. New York: Georg Olms Verlag Hildesheim.

-Comte, B. (1998). Laïcité française et conscience nationale. En M. Barlow et al. Dieu est-il lä̈que? Recherche de sens et laïcité (págs 21-50). Paris: Desclée de Brouwer.

-Condorcet, N. (1847). Oeuvres de Condorcet (Vol. VII). Paris: Firmin Didot Freres libraires.

-Courtney Murray, J. (1963). On religious liberty. America Magazine. The national catholic review. Noviembre 30, 704-706.

-Denzinger, Enrique. (1963). El magisterio de la iglesia. Manual de los símbolos, definiciones y declaraciones de la iglesia en materia de fe y costumbres. Barcelona: Editorial Herder.

-Eck, D. (1992). True liberty cherishes difference. Los Ángeles Times. Julio 5.

-Escrivá de Balaguer, J. (1967). Amar al mundo apasionadamente. 8 de octubre de 1967. Consultado http://www.es.josemariaescriva.info/articulo/amaral-mundo-apasionadamente.

-Fraile, G. (1966). Historia de la filosofía (Tomo III). Madrid: BAC.

-Godoy, O. (2003). Antología del Defensor de la paz, de Marsilio de Padua. Estudios Públicos, (90), 335-445.

-Habermas, J. \& Ratzinger, J. (2008). Entre razón y religión. Dialéctica de la secularización. México: FCE.

-Henderson, E. (1910). Documentos Históricos Selectos de la Edad Media. Londres: George Bell and Sons.

-Hervieu-Léger, D. (2001). La Religion en miettes ou la question des sectes. París: Calmann - Lévy.

-Kamen, H, (1967). Los caminos de la tolerancia. New York: McGraw-Hill.

-Kant, E. (2006). Filosofía de la Historia. México: FCE.

-Koenig, M. \& Guchteneire, P. (2007). Unesco. Democracy and Human Rights in multicultural societies. Surrey: Ashgate Publishing.

-Maritain, J. (1948). Raison et raisons, essais détachés. Paris: Egloff.

-Marsilio de Padua (1989). El Defensor de la Paz. Madrid: Tecnos.

-Poulat, E. (2003). Notre laicité publique. La France est une Republique laique. Paris: Berg International Edit.

-Riis, O. (1999). Modes of Religious Pluralism under Conditions of Globalisation. International Journal on Multicultural Societies, 1 (1), 20-34.

-Rousseau, J. J. (1820). El contrato social o principios del derecho político. Madrid: Oficina de José del Collado.

-Sartori, G. (1995). Los fundamentos del pluralismo. Leviatán (61), 111-125.

-Tocqueville, A. (1963). La Democracia en América. México- Buenos Aires: FCE. 
-Voltaire, F. (1773). Traité sur la tolérance. Lausana: Francois Grasset.

-Zmirak, J. (2010). The Ghetto Is the Future. Crisis Magazine, Noviembre 24. Recuperado de http://www.crisismagazine.com/2010/the-ghetto-is-thefuture.

Sumario: 1. ¿Ghetto o cruzada?; 2. El proceso del pluralismo y la laicidad; 3. Dos modelos de laicidad; 4. La laicidad en la doctrina de la iglesia catolica hoy; 5. El pluralismo; Conclusión; Referencias. 